\title{
A Universal CAR-NK Cell Targeting Various Epitopes of HIV-1 gp160
}

\author{
Rebecca M. Lim, ${ }^{\dagger, \|}$ Liang Rong, ${ }^{\dagger, \|}$ Anjie Zhen, ${ }^{\ddagger}$ and Jianming Xie ${ }^{*}, \dagger, \S$ \\ † Department of Pharmacology and Pharmaceutical Sciences, School of Pharmacy, University of \\ Southern California, Los Angeles, CA 90089, United States \\ $\S$ Norris Comprehensive Cancer Center, University of Southern California, Los Angeles, CA \\ 90089, United States \\ ‡ Department of Medicine, Division of Hematology and Oncology, University of California, Los \\ Angeles, CA 90095, United States \\ \|l These authors contributed equally to this work.
}

Corresponding Author E-mail: jianminx@usc.edu

I. Materials and Reagents

1. Anti-gp160 bNAbs

2. HIV gp160-expressing plasmids

3. Lentivirus plasmids

4. PCR primers

4. Other reagents

5. Cell culture

II. Experimental Procedures

1. Construction of the traditional 2G12 CAR lentiviral vector pFUW-2G12-CD28-CD3ろ

2. Conjugation of PE to DNP

3. Conjugation of bNAbs to DNP

4. Verification of DNP Conjugation to $2 \mathrm{G} 12$

5. Flow cytometry-based antibody binding assay

6. Statistical analysis

III. Figures

Figure S1: Identification of an optimal concentration of DNP-conjugated 2G12 for activating CAR-NK cells against subtype $B$ gp $160^{+}$cells

Figure S2: Universal CAR-NK cell-mediated killing of subtypes B and C gp160+ target cells

Figure S3: Targeting a mixture of subtype B and C gp160-expressing cells by CAR-NK cells supplemented with individual or combined bNAbs

Figure S4: Redirection of the universal CAR-NK cell to target malignant B cells

Figure S5: The unconjugated antibody PG9 cannot redirect anti-DNP CAR-NK cells to target gp $160^{+}$cells

Figure S6: Universal anti-DNP CAR-T cells can also kill subtype B gp160+ cells

Figure S7: Comparison of the distances of different gp160 and CD22 epitopes to the cell membrane

IV. References 


\section{MATERIALS AND REAGENTS}

\section{Anti-gp160 bNAbs}

The following reagents were obtained through the NIH AIDS Reagent Program, Division of AIDS, NIAID, NIH: 1) Anti-HIV-1 gp120 Monoclonal (PG9) from IAVI;1 2) Anti-HIV-1 gp120 Monoclonal (PGT145) from IAVI;2 3) Anti-HIV-1 gp120 Monoclonal (PG16) from IAVI;3 4) Anti-HIV-1 gp120 Monoclonal (2G12) from Polymun Scientific; 4-8 5) Anti-HIV-1 gp120 Monoclonal (PGT128) from IAVI;2, 9 6) 10-1074 MAb from Dr. Michel C. Nussenzweig; ${ }^{10} 7$ ) Anti-HIV-1 gp120 monoclonal (VRC01) from Dr. John Mascola (cat\# 12033);11 8) Anti-HIV-1 gp120 Monoclonal (IgG1 b12) from Dr. Dennis Burton and Carlos Barbas; ${ }^{12-15}$ 9) Anti-HIV-1 gp120 Monoclonal (3BNC117) from Dr. Michel C. Nussenzweig; ${ }^{10,16}$ 10) HIV-1 anti-gp41 mAb (10E8) from Dr. Mark Connors; ${ }^{17}$ 11) AntiHIV-1 gp41 Monoclonal (4E10) from Polymun Scientific;18 12) Anti-HIV-1 gp41 Monoclonal (2F5) from Polymun Scientific (cat\# 1475); ;, 19, 20

\section{HIV gp160-expressing plasmids}

The following reagents were obtained through the NIH AIDS Reagent Program, Division of AIDS, NIAID, NIH: 1) pConBgp160-opt (Cat\#11402) from Dr. Beatrice Hahn;21 and 2) pConCgp160-opt (Cat\#11407) from Dr. Beatrice Hahn. ${ }^{21,22}$

\section{Lentivirus plasmids}

The parental pFUW vector encoding an anti-CD19 CAR as well as the other three plasmids (pVSVG, pREV, and pRRE) for the third generation lentivirus system were kind gifts from Prof. Pin Wang (University of Southern California).

\section{PCR primers}

CD8 signal-BamH I-F: 5'-ACGTGGATCCGCCACCATGGCTC-3'

aDNP-R: 5'-GGGTCTGGGTGCTGGAGTTGTAGTTGCAGAGACAGTGACCAGAGTCCC-3'

CD8 hinge-F: 5'- ACTACAACTCCAGCACCCAGACCC -3'

CD28-CD3ろ-EcoR I-R: 5'-AGTCGAATTCTCATCATCTTGGTGGCAGAG-3'

2G12-R: 5'-GGGTCTGGGTGCTGGAGTTGTAGTCCTCTTGATCTCCACCCTGGTGC-3'

\section{Other reagents}

HA-tag polyclonal rabbit antibody, $F(a b) 2$-donkey anti-rabbit lgG $(H+L)$ secondary antibody $P E$, Goat anti-human IgG Fc secondary antibody PE, donkey anti-goat IgG $(\mathrm{H}+\mathrm{L})$ secondary antibody 
HRP, human IgG isotype control (Catalog No. 12000C), human anti-HLA-A2-APC (clone BB7.2), and human anti-CD56 (NCAM) APC were purchased from Thermo Fisher Scientific. The antihuman CD19 antibody (clone FMC63) was purchased from Novus Biologicals. Goat antidinitrophenol polyclonal antibody was purchased from Eagle Biosciences. CellTrace CFSE cell proliferation kit, CellTrace Blue Stain Reagent kit, LIVE/DEAD fixable aqua dead cell stain kit, Lipofectamine 2000, Geneticin (G418) solution, Magnisort streptavidin positive selection beads, Human T-Activator CD3/CD28 Dynabeads, recombinant human interleukin-2 (IL-2) (Catalog No. 34-8029-85), 8-16\% Tris-Glycine SDS-PAGE gel, Gel Code Blue Stain Reagent, 2X sample loading buffer, $40 \mathrm{kDa}$ MWCO $0.5 \mathrm{~mL}$ Zeba Spin Column, and IFN- $\gamma$ human uncoated ELISA kit were purchased from Thermo Fisher Scientific. Transblot Turbo Mini PVDF Transfer Packs, Transblot Turbo System, and Clarity Western ECL Substrate were from BioRad. Retronectin and Lenti-X Concentrator were purchased from Takara Biosciences. N-(2,4-Dinitrophenyl)-6aminocaproic acid $\mathrm{N}$-succinimidyl ester (DNP-NHS ester) and $\beta$-mercaptoethanol were purchased from Sigma Aldrich. Amicron 100kDa MWCO concentrator was purchased from Millipore. RPMI, DMEM, fetal bovine serum, non-essential amino acids, sodium pyruvate, penicillin-streptomycin-glutamine were purchased from Thermo Fisher Scientific. Ficoll-Paque Plus Reagent was purchased from GE Healthcare.

\section{Cell culture}

The NK-92Ml cell line was purchased from ATCC. The HEK293T cell line was a gift from Prof. Pin Wang (USC). The HEK293 cell line was a gift of Prof. Wei-Chiang Shen (USC). Human buffy coats were purchased from Zen-Bio Inc (Research Triangle Park, NC). Human peripheral blood mononuclear cells (PBMC) were isolated from the buffy coat using Ficoll-Paque density gradient centrifugation. NK-92MI cells were cultured in RPMI media supplemented with $20 \%$ fetal bovine serum and $0.1 \mathrm{mM}$ non-essential amino acids, $1 \mathrm{mM}$ sodium pyruvate, $0.5 \mathrm{mg} / \mathrm{mL}$ penicillin-

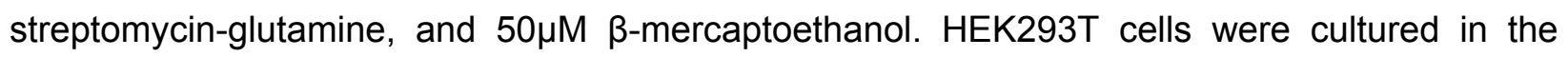
DMEM medium supplemented with $10 \%$ fetal bovine serum and $0.5 \mathrm{mg} / \mathrm{mL}$ of penicillinstreptomycin-glutamine (PSG). HEK293 cells were also cultured in DMEM medium supplemented with $10 \%$ FBS, but without PSG in order to enable for selection with Geneticin. Human PBMCs were cultured in RPMI media supplemented with $10 \%$ fetal bovine serum and $0.1 \mathrm{mM}$ nonessential amino acids, $1 \mathrm{mM}$ sodium pyruvate, $0.5 \mathrm{mg} / \mathrm{mL}$ penicillin-streptomycin-glytamine, and $50 \mu \mathrm{M} \beta$-mercaptoethanol. PBMCs were activated using Human T-Activator CD3/CD28 Dynabeads and $50 \mathrm{IU} / \mathrm{mL}$ recombinant IL-2 cytokine for 3 days before lentivirus transduction with 
anti-DNP CAR. Then primary human T-cells were further cultured using $50 \mathrm{IU} / \mathrm{mL}$ in complete RPMI medium before functional assays.

\section{SUPPLEMENTAL METHODS}

\section{Construction of the traditional 2G12 CAR lentiviral vector pFUW-2G12-CD28-CD3ろ}

The variable regions of anti-HIV-1 gp120 monoclonal antibody 2G12 were used to construct the $2 \mathrm{G} 12 \mathrm{scFv}$ [VH-(GGGGS)$)_{3}$ VL]. An additional GGGGS linker was incorporated in between HAtag and $2 \mathrm{G} 12 \mathrm{scFv}$. The gene fragment consisting of the CD8 a signal peptide, HA-tag, GGGGS linker, and 2G12 scFv was synthesized by Integrated DNA Technologies (IDT, San Diego, CA). It was then amplified by PCR using primers CD8 signal-BamH I-F and 2G12-R. This fragment was then linked together with CD8 hinge-CD28-CD3z (Ref. to Supplemental Methods II.1) by overlap PCR and digested with BamH I and EcoR I. It was then ligated into the pFUW linear vector, and the ligation product was transformed into DH5 $\alpha$ cells. Single colonies grown on LBagar plates containing $100 \mu \mathrm{g} / \mathrm{ml}$ ampicillin were picked and grown in the LB liquid medium. The plasmid was purified, sequence verified, and then used to generate lentiviral particles by calciumphosphate transfection of HEK293T cells.

\section{Conjugation of PE to DNP}

R-PE (1 mg/mL, Columbia Biosciences) was reacted with DNP-NHS ester at a molar ratio of 1:20 in $0.1 \mathrm{M}$ sodium bicarbonate buffer, $\mathrm{pH}$ 8.3. After incubation at room temperature for 4 hours, the excess DNP-NHS was removed, and the buffer was changed into $1 \mathrm{X}$ PBS with $0.5 \%$ sodium azide utilizing a $40 \mathrm{kDa}$ MWCO $0.5 \mathrm{~mL}$ Zeba Spin Column. The number of DNP moieties per RPE molecule was determined based on measuring the absorbance at $280 \mathrm{~nm}$ (for R-PE) and 360 nm (for DNP) using the Nanodrop 2000 spectrophotometer (Thermo Fisher Scientific, Waltham, MA). The average number of DNP moieties per R-PE was calculated using the following equation:

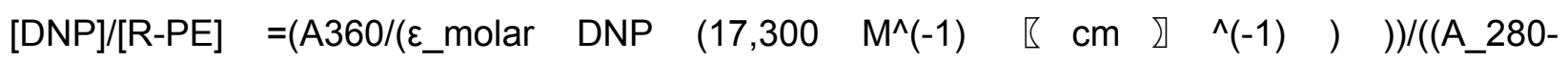
$($ A_360×0.31) $) /\left(\varepsilon \_m o l a r \operatorname{R}-P E\left(1,960,000 \mathrm{M}^{\wedge}(-1) \llbracket(\mathrm{cm} \rrbracket \wedge(-1))\right)\right)$.

\section{Conjugation of bNAbs to DNP}

All antibodies, including PG9, PGT145, PG16, 2G12, PGT128, 10-1074, VRC01, b12, 3BNC117, 10E8, 4E10, 2F5, and human $\mathrm{IgG}(1 \mathrm{mg} / \mathrm{mL})$, were conjugated to DNP using the DNP-NHS ester (molar ratio $1: 5$ ) in $0.1 \mathrm{M}$ sodium bicarbonate buffer, $\mathrm{pH}$ 8.3. After overnight incubation at $4^{\circ} \mathrm{C}$, the 
excess DNP-NHS reagent was removed, and the buffer was changed into 1X PBS buffer containing $0.5 \%$ sodium azide, using a $40 \mathrm{kDa}$ MWCO $0.5 \mathrm{~mL}$ Zeba Spin Column. The average number of DNP moieties per antibody was determined by measuring the absorbance at $280 \mathrm{~nm}$ (for antibodies) and $360 \mathrm{~nm}$ (for DNP) using a Nanodrop 2000 spectrophotometer (Thermo Fisher Scientific, Waltham, MA). The final number of DNP moieties per antibody was calculated using the following equation: $([D N P]) /\left([\right.$ Antibody] $)=\left(A 360 /\left(\varepsilon \_\right.\right.$molar DNP $\left(17,300 \mathrm{M}^{\wedge}(-1) \square \mathrm{cm}\right]^{\wedge}(-$ 1)) $)) /\left((\right.$ A_280-(A_360×0.31) $) /\left(\varepsilon \_m o l a r\right.$ Antibody $\left.\left.\left(210,000 \mathrm{M}^{\wedge}(-1) \square \mathrm{cm} \rrbracket \wedge(-1)\right)\right)\right)$.

\section{Verification of DNP Conjugation to $2 \mathrm{G} 12$}

DNP-conjugated and unconjugated antibodies $2 \mathrm{G} 12$ (2 $\mu \mathrm{g} / \mathrm{each})$ in $1 \mathrm{X}$ sample loading buffers were loaded onto pre-made 8-16\% Tris-Glycine gels. After SDS-PAGE of two identical gels, the first gel was stained with GelCode Blue Stain Coomassie reagent to confirm that both reagents were loaded in equal amounts, and the second gel was subjected to western blotting analysis. To verify DNP conjugation by western blotting, proteins were first transferred to a PVDF membrane using the Transblot Turbo Blotting System. Then the membrane was blocked for 1 hour using 5\% milk solution and incubated with a 1:500 dilution of the anti-DNP primary antibody overnight at $4^{\circ} \mathrm{C}$. The membrane was washed three times using $1 \mathrm{X}$ Tris Buffered Saline with $0.05 \%$ Tween 20 (1X TBST), incubated with a 1:5000 dilution of the donkey anti-goat IgG HRP secondary antibody for one hour at room temperature, and then washed three times using 1X TBST. Next, the membrane was incubated with an enhanced chemiluminescent (ECL) substrate and then imaged using the ChemiDoc Gel Imaging System (BioRad, Hercules, CA).

\section{Flow cytometry-based antibody binding assay}

The subtype B or C gp160-expressing HEK293 cells were stained with either VRC01, 3BNC117, $2 \mathrm{G} 12,10-1074$, PG9, 10E8, or the isotype control at a 1:3 serial dilution from $300 \mathrm{nM}$ to 0.045 $\mathrm{nM}$. In the negative control, no antibody was added. To detect antibody binding, each sample was additionally stained using a PE-conjugated anti-human $\operatorname{lgG}$ secondary antibody $(4 \mu \mathrm{g} / \mathrm{mL})$. Stained cells were analyzed by flow cytometry using the LSRII (BD Biosciences, San Jose, CA), and the average fluorescence intensity per cell was analyzed using the FlowJo software (Ashland, OR).

\section{Statistical analysis}

All cell culture experiments were performed in triplicate, and data were presented as Mean \pm SD. For verification of anti-DNP CAR-NK cell activation against subtype B gp160-expressing cells with 
DNP-conjugated 2G12, two-way ANOVA was conducted using the 2 G12 antibody, gp160negative and positive cells as the independent variables. For assessing the optimal $2 \mathrm{G} 12$ adaptor molecule concentration for universal anti-DNP CAR activation, one-way ANOVA was conducted using the 2G12 antibody as the independent variable. For validation of anti-DNP CAR-NK cell activation against subtype $B$ and subtype $C$ gp160-expressing cells by IFN- $\gamma$ production, one-way ANOVA was conducted using adaptor molecule types as the independent variable. For comparison of the different bNAbs in directing anti-DNP CAR cytotoxic activity against subtype B and subtype C gp160-expressing cells, a two-way ANOVA was conducted using antibody types and different $\mathrm{E}: \mathrm{T}$ ratios as the independent variables. For comparison of the universal to the conventional 2G12 CAR-NK cell by flow cytometry-based cytotoxicity assays, a two-way ANOVA was conducted using CAR-NK cell types and different E:T ratios as the independent variables. For the comparison of the DNP-conjugated and unconjugated PG9 antibody in activating antiDNP CAR-NK cells to produce IFN- $\gamma$, one-way ANOVA was conducted using the PG9 antibody type as the independent variable. For comparison of 10-1074 and 3BNC117 (either alone or in combination) in activating of universal CAR-NK cells, a one-way ANOVA was conducted using antibody type as the independent variable. For verification of anti-DNP CAR-T cell activation against subtype B gp160+ cells, a one-way ANOVA was conducted using antibody type as the independent variable. Both one-way and two-way ANOVA analyses were followed by either Tukey's or Dunnett's post hoc test for multiple comparisons. Significance was set at $\alpha=0.05$. To draw the saturation curves for the bNAb binding assay to subtype B and C gp160-positive cells, a nonlinear regression curve fit, using the [Agonist] vs. response (three parameters) setting, was conducted. All statistical analyses were carried out using GraphPad Prism 8 (San Diego, CA). 


\section{FIGURES}

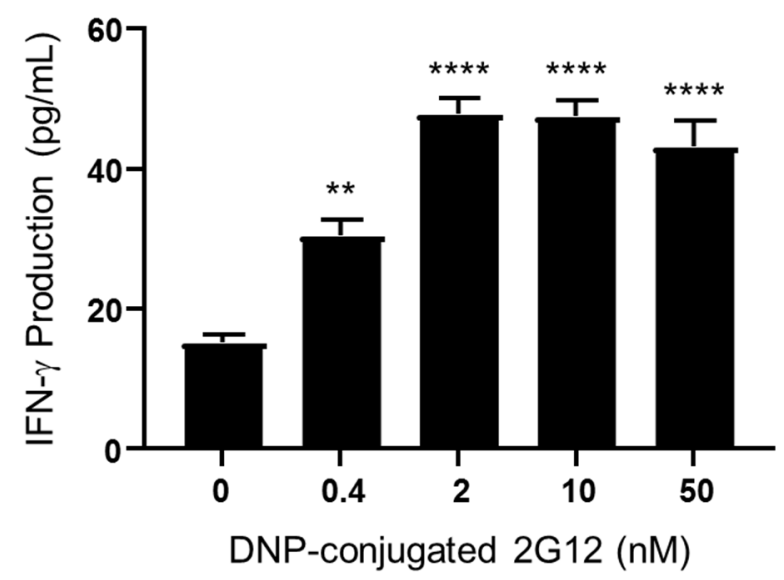

Figure S1. Identification of an optimal concentration of DNP-conjugated 2G12 for activating CARNK cells against subtype B gp $160^{+}$cells. The concentrations of IFN- $\gamma$ in the culture supernatant were determined by ELISA. Data are presented as the mean \pm SD of triplicate samples. Statistical significance is calculated by two-way ANOVA and Tukey's post-hoc analysis compared with the no antibody control. ${ }^{* *} p<0.01,{ }^{* * *} p<0.0001$. 

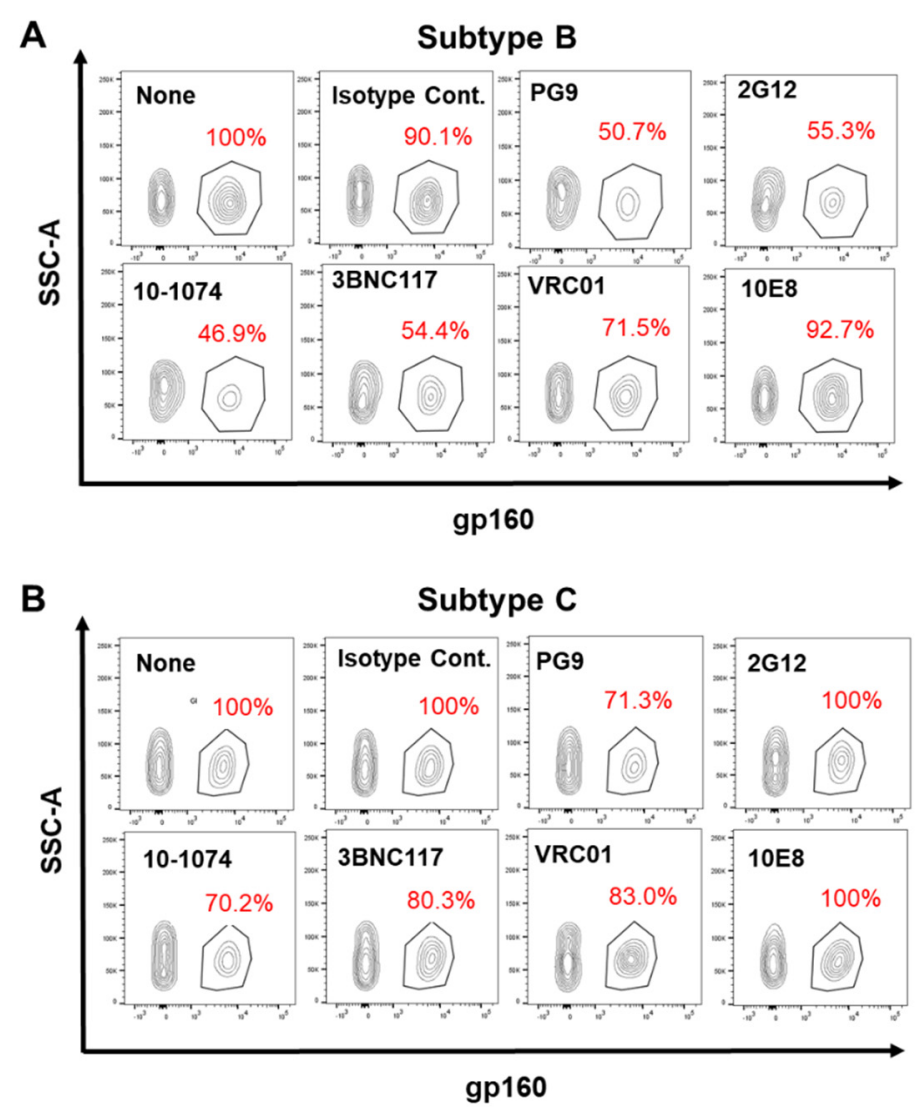

Figure S2. Universal CAR-NK cell-mediated killing of subtypes B and C gp $160^{+}$target cells. The subtype B or C gp160+ HEK293 cells were labelled with CFSE dye, while the gp160- HEK293 cells were unlabelled. Anti-DNP CAR-NK cells were co-cultured with a $1: 1$ mixture of gp $160^{+}$and gp160- cells at different E:T ratios (25:1, 5:1, and 1:1), with or without DNP-conjugated antibodies (2 nM). After an eight-hour incubation, cells were stained with an APC-conjugated anti-human HLA-A2 antibody and the aqua live/dead cell stain reagent, and then subjected to flow cytometric analysis. The gp160+ and gp160- HEK293 cells were gated as HLA-A2-positive. Live HEK293 cells after co-culture with CAR-NK cells at the 25:1 E:T ratio are shown above. The percentages in red represent the remaining live gp $160^{+}$cells compared with the no antibody control (none). 


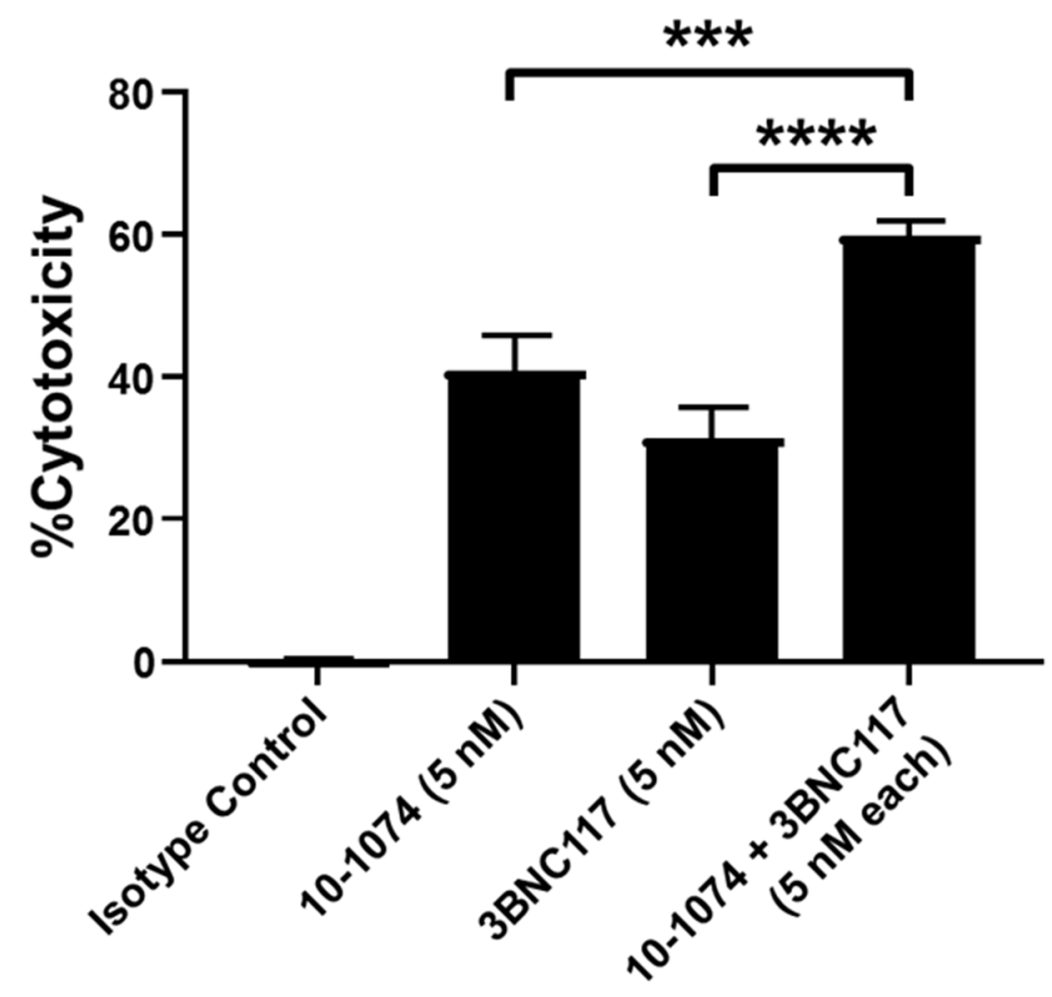

Figure S3. Targeting a mixture of subtype B and C gp160-expressing cells by CAR-NK cells supplemented with individual or combined bNAbs. The percentage of CAR-NK cell cytotoxicity was calculated as $[(A-B) / A \times 100]$, in which $A$ and $B$ were the numbers of viable gp $160^{+}$cells (both subtypes $B$ and $C$ ) after the cell co-culture was incubated without and with DNP-conjugated antibodies, respectively. Data are presented as the mean \pm SD of triplicate samples. Statistical significance is calculated by two-way ANOVA and Tukey's post-hoc analysis. ${ }^{* * *} p<0.001,{ }^{* * *}$ $p<0.0001$ vs. the isotype control. 


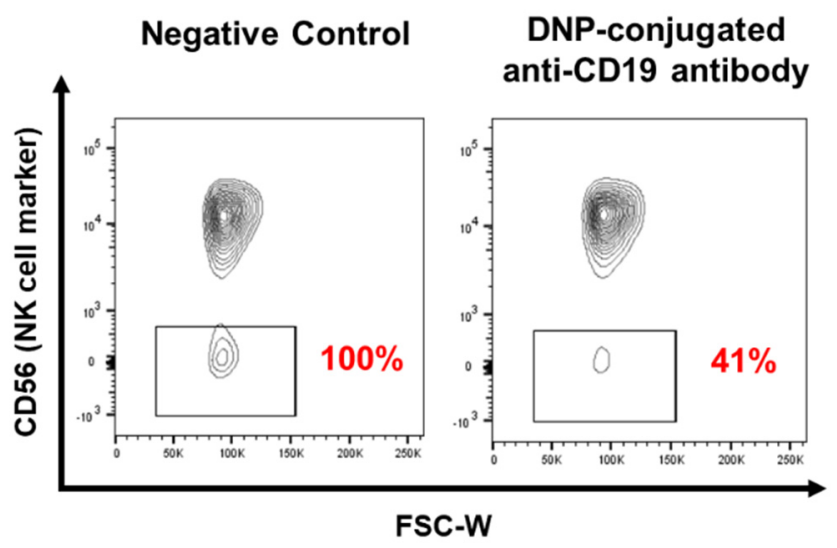

Figure S4. Redirection of the universal CAR-NK cell to target malignant B cells. Anti-DNP CARNK cells were co-cultured with REH cells at a 25:1 E:T ratio with or without a DNP-conjugated anti-CD19 antibody (clone FMC63, $50 \mathrm{nM}$ ). After overnight incubation, the percentages of remaining REH cells were determined by flow cytometry. CD56 is a cell surface marker for NK cells. 


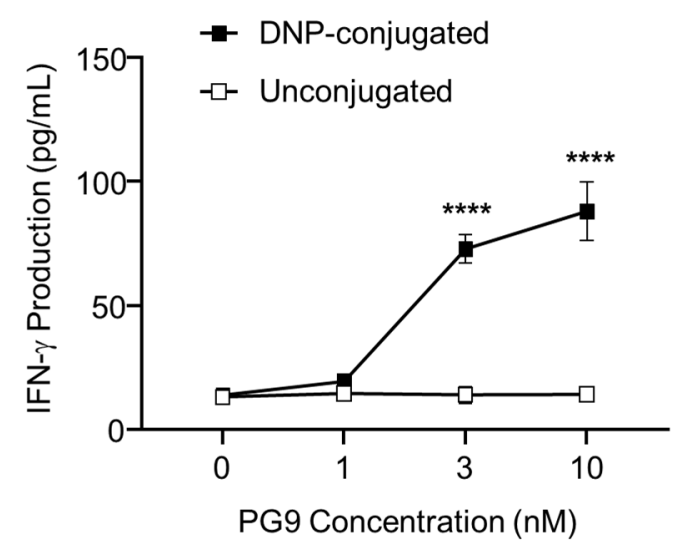

Figure S5. The unconjugated antibody PG9 cannot redirect anti-DNP CAR-NK cells to target gp $160^{+}$cells. Anti-DNP CAR-NK cells were co-cultured with the subtype B gp160-expressing cells in the presence of DNP-conjugated and unconjugated antibody PG9. The concentrations of IFN$\gamma$ in the culture supernatant were determined by ELISA. Data are presented as the mean \pm SD of triplicate samples. Statistical significance is calculated by two-way ANOVA and Tukey's post-hoc analysis compared with the unconjugated PG9. ${ }^{* * * *} p<0.0001$. 


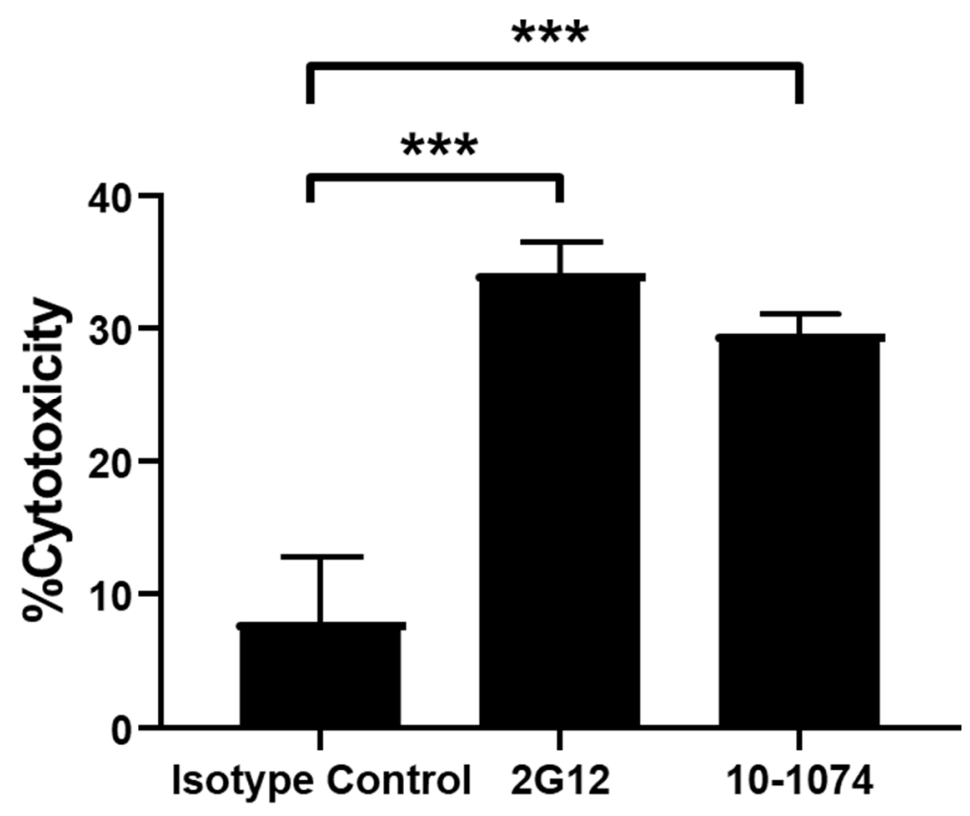

Figure S6. Universal anti-DNP CAR-T cells can also kill subtype B gp160+ cells. Primary human anti-DNP CAR-T cells were co-cultured with CellTrace Blue-labeled HEK293 gp160+ Subtype B cells at a 1:1 E:T ratio in the presence of $10 \mathrm{nM}$ of DNP-conjugated bNAbs or isotype control. After a 48-hour incubation at $37^{\circ} \mathrm{C}$, cells were collected and stained with a FITC-conjugated antihuman CD3 antibody and an aqua live/dead cell stain reagent, followed by flow cytometric analysis. The percentage of CAR-T cell cytotoxicity was calculated as [(A-B)/Ax100], in which $A$ and $B$ were the numbers of viable gp $160^{+}$cells after the cell co-culture was incubated without and with the addition of DNP-conjugated antibodies, respectively. Data are presented as the mean \pm SD of triplicate samples. Statistical significance is calculated by one-way ANOVA and Dunnett's post-hoc analysis compared to the isotype control. ${ }^{* *} p<0.01$, ${ }^{* * *} p<0.001$. n.s.: not significant. 


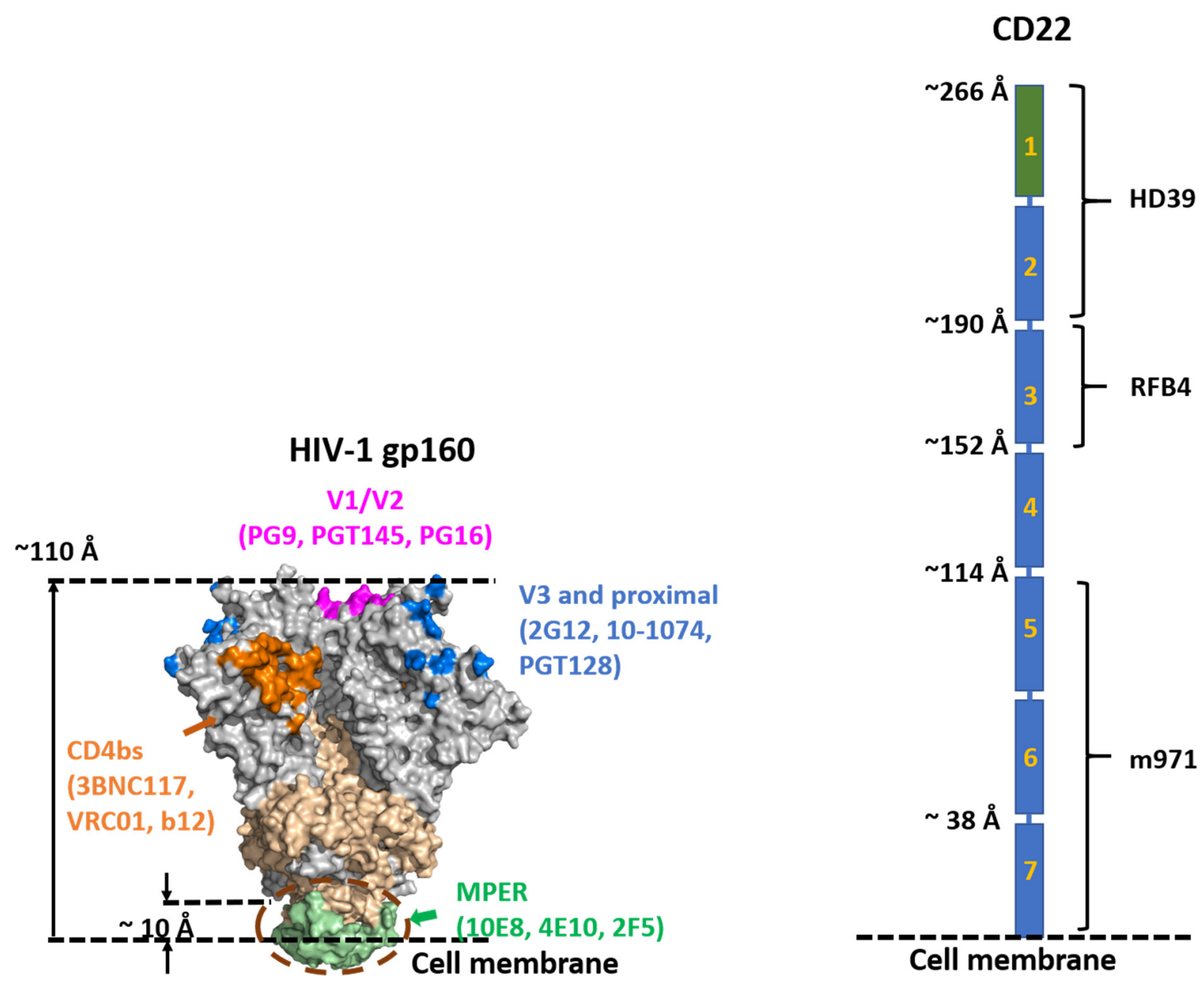

Figure S7. Comparison of the distances of different gp160 and CD22 epitopes to the cell membrane. The extracellular domain of CD22 consists of seven lg-like domains. Based on the structure of CD22 (PDB ID: 5VKJ), the average length of each Ig-like domain is estimated to be about $38 \AA$. 


\section{REFERENCES}

1. Walker, L. M.; Phogat, S. K.; Chan-Hui, P. Y.; Wagner, D.; Phung, P.; Goss, J. L.; Wrin, T.; Simek, M. D.; Fling, S.; Mitcham, J. L.; Lehrman, J. K.; Priddy, F. H.; Olsen, O. A.; Frey, S. M.; Hammond, P. W.; Kaminsky, S.; Zamb, T.; Moyle, M.; Koff, W. C.; Poignard, P.; Burton, D. R., Broad and potent neutralizing antibodies from an African donor reveal a new HIV-1 vaccine target. Science 2009, 326 (5950), 285-9.

2. Walker, L. M.; Huber, M.; Doores, K. J.; Falkowska, E.; Pejchal, R.; Julien, J. P.; Wang, S. K.; Ramos, A.; Chan-Hui, P. Y.; Moyle, M.; Mitcham, J. L.; Hammond, P. W.; Olsen, O. A.; Phung, P.; Fling, S.; Wong, C. H.; Phogat, S.; Wrin, T.; Simek, M. D.; Protocol, G. P. I.; Koff, W. C.; Wilson, I. A.; Burton, D. R.; Poignard, P., Broad neutralization coverage of HIV by multiple highly potent antibodies. Nature 2011, 477 (7365), 466-70.

3. Walker, L. M.; Phogat, S. K.; Chan-Hui, P. Y.; Wagner, D.; Phung, P.; Goss, J. L.; Wrin, T.; Simek, M. D.; Fling, S.; Mitcham, J. L.; Lehrman, J. K.; Priddy, F. H.; Olsen, O. A.; Frey, S. M.; Hammond, P. W.; Protocol, G. P. I.; Kaminsky, S.; Zamb, T.; Moyle, M.; Koff, W. C.; Poignard, P.; Burton, D. R., Broad and potent neutralizing antibodies from an African donor reveal a new HIV-1 vaccine target. Science 2009, 326 (5950), 285-9.

4. Buchacher, A.; Predl, R.; Strutzenberger, K.; Steinfellner, W.; Trkola, A.; Purtscher, M.; Gruber, G.; Tauer, C.; Steindl, F.; Jungbauer, A.; et al., Generation of human monoclonal antibodies against HIV-1 proteins; electrofusion and Epstein-Barr virus transformation for peripheral blood lymphocyte immortalization. AIDS Res Hum Retroviruses 1994, 10 (4), 359-69.

5. Crawford, J. M.; Earl, P. L.; Moss, B.; Reimann, K. A.; Wyand, M. S.; Manson, K. H.; Bilska, M.; Zhou, J. T.; Pauza, C. D.; Parren, P. W.; Burton, D. R.; Sodroski, J. G.; Letvin, N. L.; Montefiori, D. C., Characterization of primary isolate-like variants of simianhuman immunodeficiency virus. J Virol 1999, 73 (12), 10199-207.

6. Etemad-Moghadam, B.; Sun, Y.; Nicholson, E. K.; Karlsson, G. B.; Schenten, D.; Sodroski, J., Determinants of neutralization resistance in the envelope glycoproteins of a simian-human immunodeficiency virus passaged in vivo. J Virol 1999, 73 (10), 8873-9.

7. Mascola, J. R.; Lewis, M. G.; Stiegler, G.; Harris, D.; VanCott, T. C.; Hayes, D.; Louder, M. K.; Brown, C. R.; Sapan, C. V.; Frankel, S. S.; Lu, Y.; Robb, M. L.; Katinger, H.; Birx, D. L., Protection of Macaques against pathogenic simian/human immunodeficiency virus 89.6PD by passive transfer of neutralizing antibodies. J Virol 1999, 73 (5), 4009-18.

8. Trkola, A.; Purtscher, M.; Muster, T.; Ballaun, C.; Buchacher, A.; Sullivan, N.; Srinivasan, K.; Sodroski, J.; Moore, J. P.; Katinger, H., Human monoclonal antibody $2 \mathrm{G} 12$ defines a distinctive neutralization epitope on the gp120 glycoprotein of human immunodeficiency virus type 1. J Virol 1996, 70 (2), 1100-8.

9. Pejchal, R.; Doores, K. J.; Walker, L. M.; Khayat, R.; Huang, P. S.; Wang, S. K.; Stanfield, R. L.; Julien, J. P.; Ramos, A.; Crispin, M.; Depetris, R.; Katpally, U.; Marozsan, A.; Cupo, A.; Maloveste, S.; Liu, Y.; McBride, R.; Ito, Y.; Sanders, R. W.; Ogohara, C.; Paulson, J. C.; Feizi, T.; Scanlan, C. N.; Wong, C. H.; Moore, J. P.; Olson, W. C.; Ward, A. B.; Poignard, P.; Schief, W. R.; Burton, D. R.; Wilson, I. A., A potent and broad neutralizing antibody recognizes and penetrates the HIV glycan shield. Science 2011, 334 (6059), 1097-103. 
10. Shingai, M.; Nishimura, Y.; Klein, F.; Mouquet, H.; Donau, O. K.; Plishka, R.; BucklerWhite, A.; Seaman, M.; Piatak, M., Jr.; Lifson, J. D.; Dimitrov, D. S.; Nussenzweig, M. C.; Martin, M. A., Antibody-mediated immunotherapy of macaques chronically infected with SHIV suppresses viraemia. Nature 2013, 503 (7475), 277-80.

11. Wu, X.; Yang, Z. Y.; Li, Y.; Hogerkorp, C. M.; Schief, W. R.; Seaman, M. S.; Zhou, T.; Schmidt, S. D.; Wu, L.; Xu, L.; Longo, N. S.; McKee, K.; O'Dell, S.; Louder, M. K.; Wycuff, D. L.; Feng, Y.; Nason, M.; Doria-Rose, N.; Connors, M.; Kwong, P. D.; Roederer, M.; Wyatt, R. T.; Nabel, G. J.; Mascola, J. R., Rational design of envelope identifies broadly neutralizing human monoclonal antibodies to HIV-1. Science 2010, 329 (5993), 856-61.

12. Burton, D. R.; Barbas, C. F., 3rd; Persson, M. A.; Koenig, S.; Chanock, R. M.; Lerner, R. A., A large array of human monoclonal antibodies to type 1 human immunodeficiency virus from combinatorial libraries of asymptomatic seropositive individuals. Proc Natl Acad Sci U S A 1991, 88 (22), 10134-7.

13. Barbas, C. F., 3rd; Bjorling, E.; Chiodi, F.; Dunlop, N.; Cababa, D.; Jones, T. M.; Zebedee, S. L.; Persson, M. A.; Nara, P. L.; Norrby, E.; et al., Recombinant human Fab fragments neutralize human type 1 immunodeficiency virus in vitro. Proc Natl Acad Sci U S A 1992, 89 (19), 9339-43.

14. Roben, P.; Moore, J. P.; Thali, M.; Sodroski, J.; Barbas, C. F., 3rd; Burton, D. R., Recognition properties of a panel of human recombinant Fab fragments to the CD4 binding site of gp120 that show differing abilities to neutralize human immunodeficiency virus type 1. J Virol 1994, 68 (8), 4821-8.

15. Burton, D. R.; Pyati, J.; Koduri, R.; Sharp, S. J.; Thornton, G. B.; Parren, P. W.; Sawyer, L. S.; Hendry, R. M.; Dunlop, N.; Nara, P. L.; et al., Efficient neutralization of primary isolates of HIV-1 by a recombinant human monoclonal antibody. Science 1994, 266 (5187), 1024-7.

16. Scheid, J. F.; Mouquet, H.; Ueberheide, B.; Diskin, R.; Klein, F.; Oliveira, T. Y.; Pietzsch, J.; Fenyo, D.; Abadir, A.; Velinzon, K.; Hurley, A.; Myung, S.; Boulad, F.; Poignard, P.; Burton, D. R.; Pereyra, F.; Ho, D. D.; Walker, B. D.; Seaman, M. S.; Bjorkman, P. J.; Chait, B. T.; Nussenzweig, M. C., Sequence and structural convergence of broad and potent HIV antibodies that mimic CD4 binding. Science 2011, 333 (6049), 1633-7.

17. Huang, J.; Ofek, G.; Laub, L.; Louder, M. K.; Doria-Rose, N. A.; Longo, N. S.; Imamichi, H.; Bailer, R. T.; Chakrabarti, B.; Sharma, S. K.; Alam, S. M.; Wang, T.; Yang, Y.; Zhang, B.; Migueles, S. A.; Wyatt, R.; Haynes, B. F.; Kwong, P. D.; Mascola, J. R.; Connors, M., Broad and potent neutralization of HIV-1 by a gp41-specific human antibody. Nature 2012, 491 (7424), 406-12.

18. Stiegler, G.; Kunert, R.; Purtscher, M.; Wolbank, S.; Voglauer, R.; Steindl, F.; Katinger, $\mathrm{H}$., A potent cross-clade neutralizing human monoclonal antibody against a novel epitope on gp41 of human immunodeficiency virus type 1. AIDS Res Hum Retroviruses 2001, 17 (18), 1757-65. 
19. Purtscher, M.; Trkola, A.; Gruber, G.; Buchacher, A.; Predl, R.; Steindl, F.; Tauer, C.; Berger, R.; Barrett, N.; Jungbauer, A.; et al., A broadly neutralizing human monoclonal antibody against gp41 of human immunodeficiency virus type 1. AIDS Res Hum Retroviruses 1994, 10 (12), 1651-8.

20. Purtscher, M.; Trkola, A.; Grassauer, A.; Schulz, P. M.; Klima, A.; Dopper, S.; Gruber, G.; Buchacher, A.; Muster, T.; Katinger, H., Restricted antigenic variability of the epitope recognized by the neutralizing gp41 antibody 2F5. AIDS 1996, 10 (6), 587-93.

21. Andre, S.; Seed, B.; Eberle, J.; Schraut, W.; Bultmann, A.; Haas, J., Increased immune response elicited by DNA vaccination with a synthetic gp120 sequence with optimized codon usage. J Virol 1998, 72 (2), 1497-503.

22. Kothe, D. L.; Li, Y.; Decker, J. M.; Bibollet-Ruche, F.; Zammit, K. P.; Salazar, M. G.; Chen, Y.; Weng, Z.; Weaver, E. A.; Gao, F.; Haynes, B. F.; Shaw, G. M.; Korber, B. T.; Hahn, B. H., Ancestral and consensus envelope immunogens for HIV-1 subtype C. Virology 2006, 352 (2), 438-49. 